\title{
Syringo-Subarachnoid Shunt Placement: A Minimally Invasive Technique Using Fixed Tubular Retractors-Three Case Reports and Literature Review
}

\author{
UMESH SRIKANTHA, MCH, AKSHAY HARI, DNB, YADHU K LOKANATH, MCH, NIRMALA S, MCH, \\ RAVI GOPAL VARMA, MCH \\ Department of Neurosurgery, Aster CMI Hospital, Karnataka, India
}

\begin{abstract}
Background: Placement of a syringo-subarachnoid shunt as a surgical management for syringomyelia has been well described in the literature. Good results in terms of clinical and radiological improvement have been documented especially for posttraumatic syringomyelia. Traditionally, this has been performed using open approaches which are fraught with risks of cerebrospinal fluid leak, delayed wound healing, and increased postoperative pain. With the help of minimally invasive techniques that are currently being used to treat various degenerative spinal disorders, most of these complications may be minimized. However, few reports in literature describe similar approaches for accessing intradural intramedullary spinal cord lesions and especially for syringomyelia.

Methods: Retrospective case review: using a 22-mm tubular retractor, a laminotomy was performed, durotomy done, and spinal cord identified. Myelotomy was performed at the dorsal root entry zone, syrinx visualized and entered, followed by placement of syringo-subarachnoid shunt.

Results: Three male patients aged 44, 57, and 37 underwent placement of syringo-subarachnoid shunts using minimally invasive fixed tubular retractors. Indications included posttraumatic or postsurgical spinal cord syrinx. Follow-up period was 1 year in all cases. There were no neurological or technique-related complications. All patients showed clinical improvement upon subsequent follow up.

Conclusions: Our clinical experience on the treatment of syringomyelia via a minimally invasive fixed tubular retractor is presented. We find that this is an ideal approach for placement of syringo-subarachnoid shunts, as it provides direct access to the lesion with minimal collateral damage and wound-related complications.

Level of Evidence: 4

Clinical Relevance: Relevant - in demonstrating the effectiveness of an already established procedure through a novel, minimally invasive approach which has the potential to significantly reduce the overall morbidity, in view of the inherent approach-related benefits as compared to conventional open approaches.
\end{abstract}

Minimally Invasive Surgery

Keywords: minimally invasive approach, syringo-subarachnoid shunt, syringomyelia, intradural intramedullary lesions

\section{INTRODUCTION}

Syringomyelia is a pathology characterized by accumulation of fluid within the spinal cord. ${ }^{1}$ The exact pathogenesis has not been clearly understood; however, it is believed to be a result of abnormal cerebrospinal fluid (CSF) dynamics or obstruction of CSF flow below the cervico-medullary junction. ${ }^{2}$ Multiple etiologies have been described ranging from Chiari malformation, spinal cord tumors, infection, trauma, tethered cord, inflammation, and previous history of surgery. ${ }^{3}$ The most common cause of spinal cord syrinx is Chiari malformation. Posttraumatic syringomyelia, although rare, is believed to be the second most common etiology. ${ }^{4}$
The management of syringomyelia entails the treatment of the primary causative factors. In most cases, the syrinx spontaneously undergoes resolution after removal of the offending agents such as foramen magnum decompression for Chiari malformation, excision of a spinal tumor, or release of tethered cord, as a result of re-establishment of the normal CSF dynamics. ${ }^{5-7}$ In the case of isolated spinal cord syringomyelia such as posttraumatic syrinx, syringo-subarachnoid shunting has become the treatment of choice. ${ }^{8}$ Good results in terms of clinical and radiological improvement have been documented in the literature. ${ }^{9-12}$ 


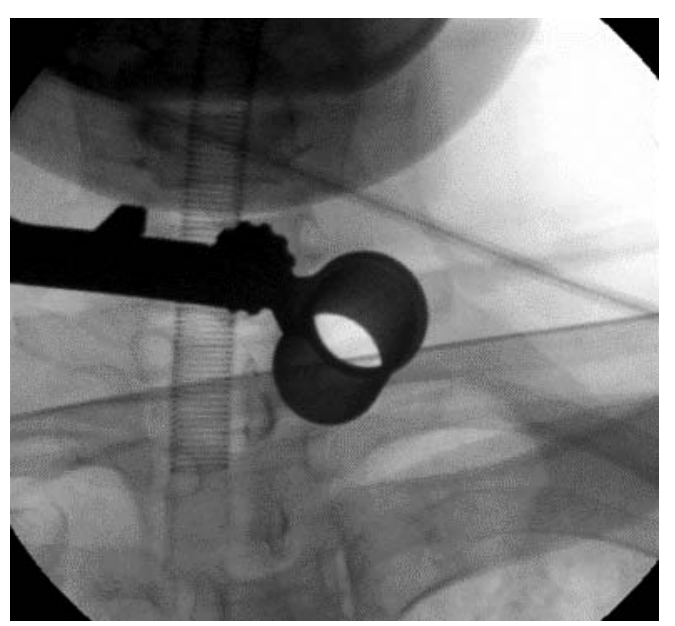

Figure 1. Intraoperative fluoroscopy demonstrating localization of required level and the fixed tubular retractor in situ.

However, traditionally, this has been performed using open approaches. Conventional open intradural surgeries require large incisions with increased muscle dissection, extensive bony resection for wide laminectomy, leading to greater risk of bleeding, prolonged postoperative pain, delayed wound healing, pseudomeningocele formation, and CSF leak. ${ }^{13-15}$ With the advent of minimally invasive surgical techniques, many of these complications have been overcome to a large extent.

While minimally invasive surgeries using tubular retractors are nowadays performed routinely for many patients with spondylosis, disc prolapse, and fusions, very few reports in literature describe similar approaches for accessing intradural intramedullary spinal cord lesions and especially for syringomyelia.

Our clinical experience on the treatment of syringomyelia via minimally invasive fixed tubular retractors is being presented.

\section{METHODS}

\section{Surgical Technique}

After induction under general anesthesia, the patient was positioned prone over bolsters, with the head fixed on pins (for cervico-dorsal lesions) or a head support (for dorso-lumbar lesions). A paramedian vertical incision of $2.5 \mathrm{~cm}$ was marked at the desired level, corresponding to the maximum syrinx diameter on magnetic resonance imaging (MRI), and confirmed with fluoroscopy. The surgical area was then prepared sterile and draped. An incision was made over the previously marked area and deepened up to the fascia. Access was then obtained using the MetRx tube dilator system (Medtronic Sofamor Danek, Memphis, TN). A 22-mm diameter MetRx tube working port was inserted over the dilators and secured in place by a flexible arm attached to the operating table. Once the dilators were removed, the lamina and interlaminar space was visualized. The correct level was confirmed using intraoperative fluoroscopy (Figure 1). Further steps were carried out by using an operating microscope.

Using standard microsurgical techniques, the fascia and muscles were dissected, and a laminotomy was performed. Care was taken not to disrupt the facets. Durotomy was performed by opening the dura in the midline and held in place by dural tackup sutures. The arachnoid was opened carefully and any adhesions if found were released. A sharp myelotomy was performed at the dorsal root entry zone (DREZ) after identifying the spinal cord midline. Gentle dissection was done to expose the syrinx cavity and allow a free flow of CSF.

A cut piece of lumbar drainage catheter (used commonly for theco-peritoneal shunts) was fashioned to a length of around 8 to $10 \mathrm{~cm}$. The proximal end of the cut shunt tube was placed into the syrinx cavity and advanced cranially to more than half its length. CSF egress through the distal end of the shunt tube was visually confirmed. The distal end was then placed in the subarachnoid space and was anchored using 6-0 silk. A water-tight dural closure was performed with intermittent sutures using 6-0 Mersilk (Ethicon, Inc.), 10-mm reverse cutting needle, three-eighths of a circle. This allows for easy maneuverability within the narrow tube and does not tear through or make dural holes. A dural substitute (Duragen, Integra Life Sciences) was used to cover the dura. Occasionally, dural sealants such as fibrin glue (Tisseel; Baxter International) were used to augment the water-tight closure. Complete hemostasis was achieved, and after removal of the working port, the muscle layers were noted to fall back and occlude the dead space. The wound was then closed in layers.

\section{ILLUSTRATIVE CASES}

\section{Case 1}

A 44-year-old male presented with nonprogressive numbness in his left hand for 2 years, associated with a bandlike tightness around the chest (Table 1). $\mathrm{He}$ was noted to have wasting of muscles in both 
Table 1. Patient case details.

\begin{tabular}{|c|c|c|c|c|c|c|c|}
\hline No. & $\begin{array}{l}\text { Age, } \\
\text { Sex }\end{array}$ & Clinical Features & $\begin{array}{l}\text { Duration of } \\
\text { Symptoms } \\
\text { (months) }\end{array}$ & Syrinx Levels & Shunt Location & $\begin{array}{l}\text { Duration of } \\
\text { Surgery } \\
\text { (minutes) }\end{array}$ & $\begin{array}{l}\text { Estimated } \\
\text { Blood Loss } \\
\quad(\mathrm{mL})\end{array}$ \\
\hline 1 & $44 \mathrm{M}$ & $\begin{array}{l}\text { Fall from height, left hand numbness, } \\
\text { chest tightness, hand muscle wasting }\end{array}$ & 24 & $\mathrm{CV}$ junction to D11 & D1-D2 & 75 & 50 \\
\hline 2 & $57 \mathrm{M}$ & $\begin{array}{l}\text { Motor vehicle accident, chest tightness, } \\
\text { paraparesis }\end{array}$ & 24 & $\mathrm{C} 3$ to $\mathrm{D} 2$ and $\mathrm{D} 3$ to $\mathrm{L} 1$ & D1-D2 and D10-D11 & 140 & 80 \\
\hline 3 & $37 \mathrm{M}$ & $\begin{array}{l}\text { Post spine tumor excision, right upper } \\
\text { limb wasting and weakness, lower limb } \\
\text { spasticity }\end{array}$ & 36 & C2 to D3 & $\mathrm{C} 7-\mathrm{T} 1$ & 90 & 60 \\
\hline
\end{tabular}

upper limbs, weakness of both shoulders with poor hand grip, and mild sensory loss in both thighs. There were no bowel or bladder disturbances. The patient gave a history of a fall from a height in 1998 and had sustained injury to his back and pelvis. He did not have any previous surgeries.
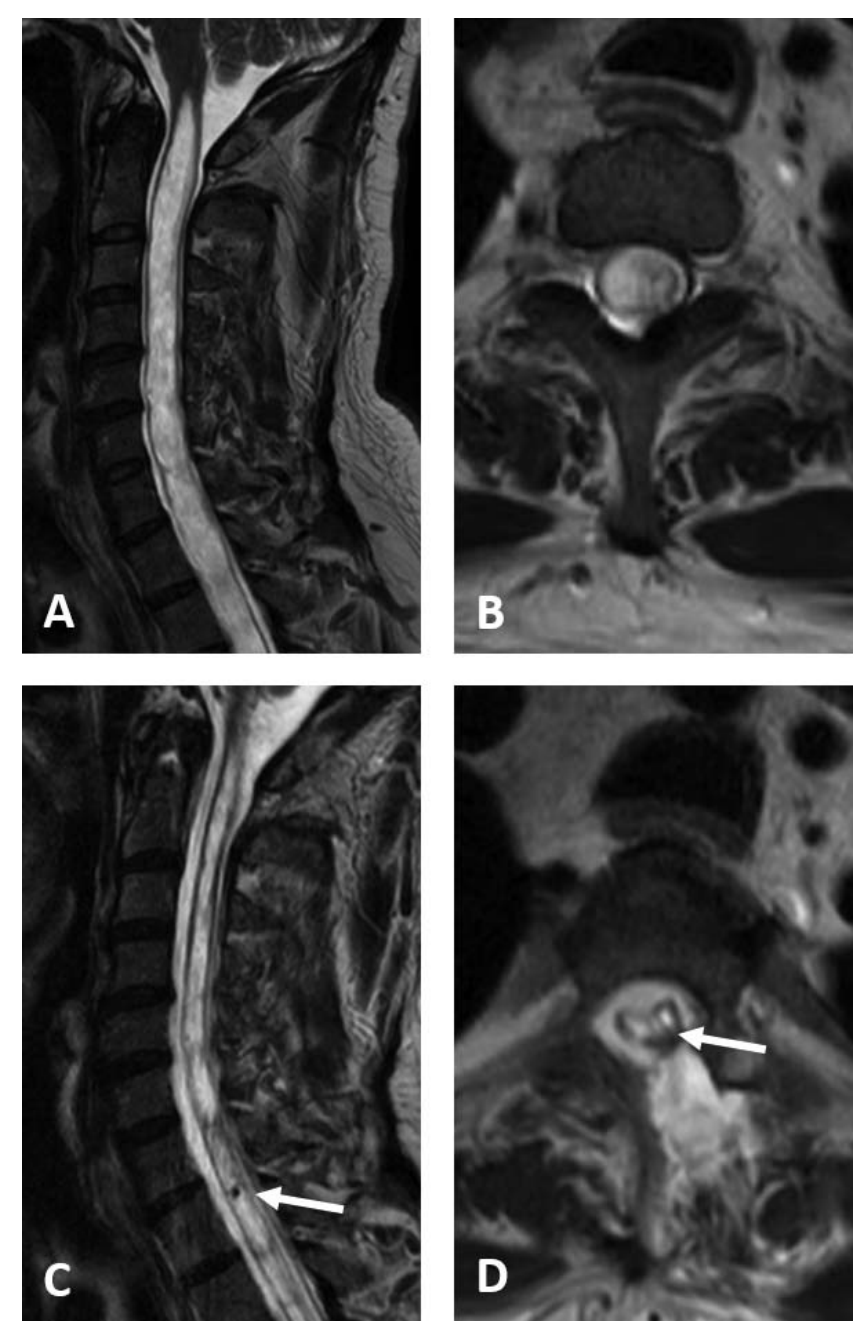

Figure 2. Case 1. (A) and (B) Preoperative magnetic resonance imaging T2 weighted sagittal and axial (at D2) showing extensive cervico-dorsal syringomyelia. (C) and (D) Postoperative magnetic resonance imaging T2 weighted sagittal and axial (at D2) showing resolution of syrinx with laminotomy defect and shunt tube in place (arrows).
MRI of the spine showed extensive cervico-dorsal syrinx from cranio-vertebral (CV) junction to D11 level, with an old anterior wedge compression fracture of the L1 vertebral body (Figures 2A and B).

\section{Case 2}

A 57-year-old male suffered a motor vehicle accident in March 2015 and sustained injury to the spine and lower extremities with weakness of both lower limbs since then (Table 1). He underwent surgery for a left femur fracture followed by spine surgery in August 2015. He presented to us with complaints of worsening pain and weakness of lower limbs with bandlike tightening sensation around his chest and abdomen. His power in both the lower limbs was grade 2, and sensations were diminished below D10 dermatome.

MRI of the spine showed 2 syringeal cavities in the cervical cord separated by a thin fibrous septum-smaller syrinx extending from C3 to D2 vertebral body level, long segment syrinx seen in the dorso-lumbar cord with thin septations within, extending from D3 to L1 level (Figures 3A-C).

\section{Case 3}

A 37-year-old male, who was operated on for an intramedullary tumor in the cervical spine 3 years prior, presented with history of weakness of the right upper and lower limbs (Table 1). The weakness was seen after the surgery but became gradually progressive with no aggravating or relieving factors. He also noted a bandlike sensation around his upper chest with numbness and stiffness in both lower limbs. He was found to have significant muscle wasting with grade 3 power in his right upper and lower limbs with hypoesthesia below D4 and severe spasticity of all 4 limbs.

MRI of the spine showed postoperative changes seen posteriorly from C3-C6 level, with a long 

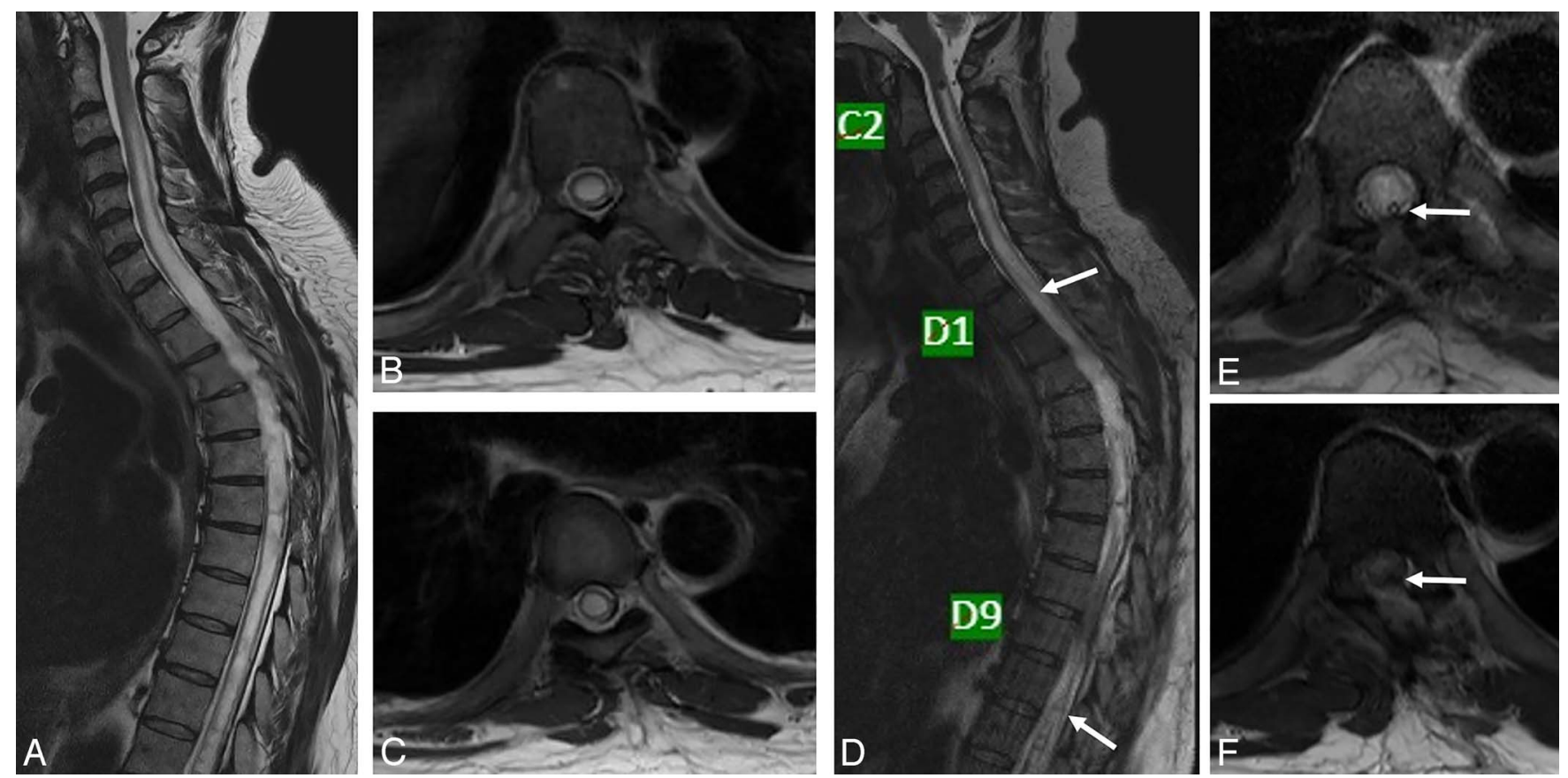

D

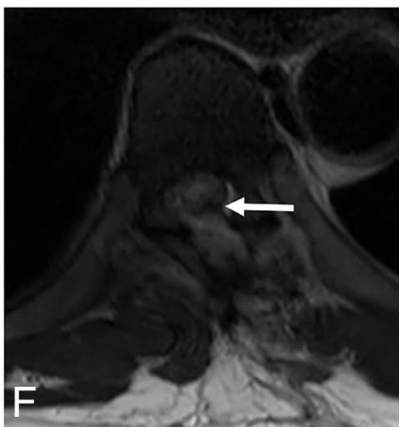

Figure 3. Case 2. (A), (B), and (C) Preoperative magnetic resonance imaging T2 weighted sagittal and axial (at D2, D10), showing 2 syringeal cavities separated by a thin fibrous septum near D6. (D), (E), and (F) Postoperative magnetic resonance imaging T2 weighted sagittal and axial (at D2, D10), showing resolution of syrinx with laminotomy defect and shunt tube in place (arrows).

segment syrinx extending from the $\mathrm{C} 2$ vertebral body to D2-3 level, and thin septations within. There was thinning of the cord from the C3-4 to C5-6 level. No evidence of Chiari malformation (Figures 4A and B).

All the patients underwent minimally invasive surgery (MIS) placement of a syringo-subarachnoid shunt. In case 1, a single shunt was placed at the D1-D2 level. In case 2, there were 2 distinct syrinx cavities, and hence, it was decided to place 2 separate shunts-1 at D1-D2 and another at D10D11 levels. This patient had already undergone previous midline laminectomies, and hence, care was taken in identifying the bone edges and the dura. In case 3, there was a smaller syrinx adjacent to the main cavity. A communication was established between the 2 , and then a shunt was placed at the level of C7-D1.

Postoperatively, they improved neurologically and were mobilized on post-operative day 1 . Postoperative MRI done at 2 weeks after surgery showed resolution of the syrinx (Figures $1 \mathrm{C}$ and D, 2D-F, 3C and D). All patients were followed up for a minimum of 1 year with significant symptom relief, preserved neurological status, and no shuntrelated complications.

\section{DISCUSSION}

Syringomyelia is a disease entity that has not been perfectly understood. ${ }^{2}$ Consequently, the ideal management for syringomyelia is also not clear. ${ }^{5}$ Optimally, the primary causative factor such as Chiari malformation or spinal tumor needs to be addressed, after which in most cases the syrinx resolves spontaneously. ${ }^{6,16}$ However, situations do arise where a direct drainage of the syrinx is warranted, when no other obvious etiology is found. In such cases, syringo-subarachnoid shunting has become a well-described technique for the treatment of isolated syringomyelia. Various reports in the literature support the rationale of this procedure for decompressing the syrinx cavity and providing an alternate CSF diversion pathway with moderate to good results. ${ }^{17-20}$ As with any shunt procedure, various complications leading to shunt failure have also been reported in the past, ranging from infection, shunt blockage, shunt displacement, arachnoid scarring, and inadequate drainage due to loculations or septations within the syrinx itself. $^{21,22}$ However, the benefits seem to outweigh the risks due to the lack of availability of a suitably better alternative, especially with newer microsurgical techniques and current advances in shunt 

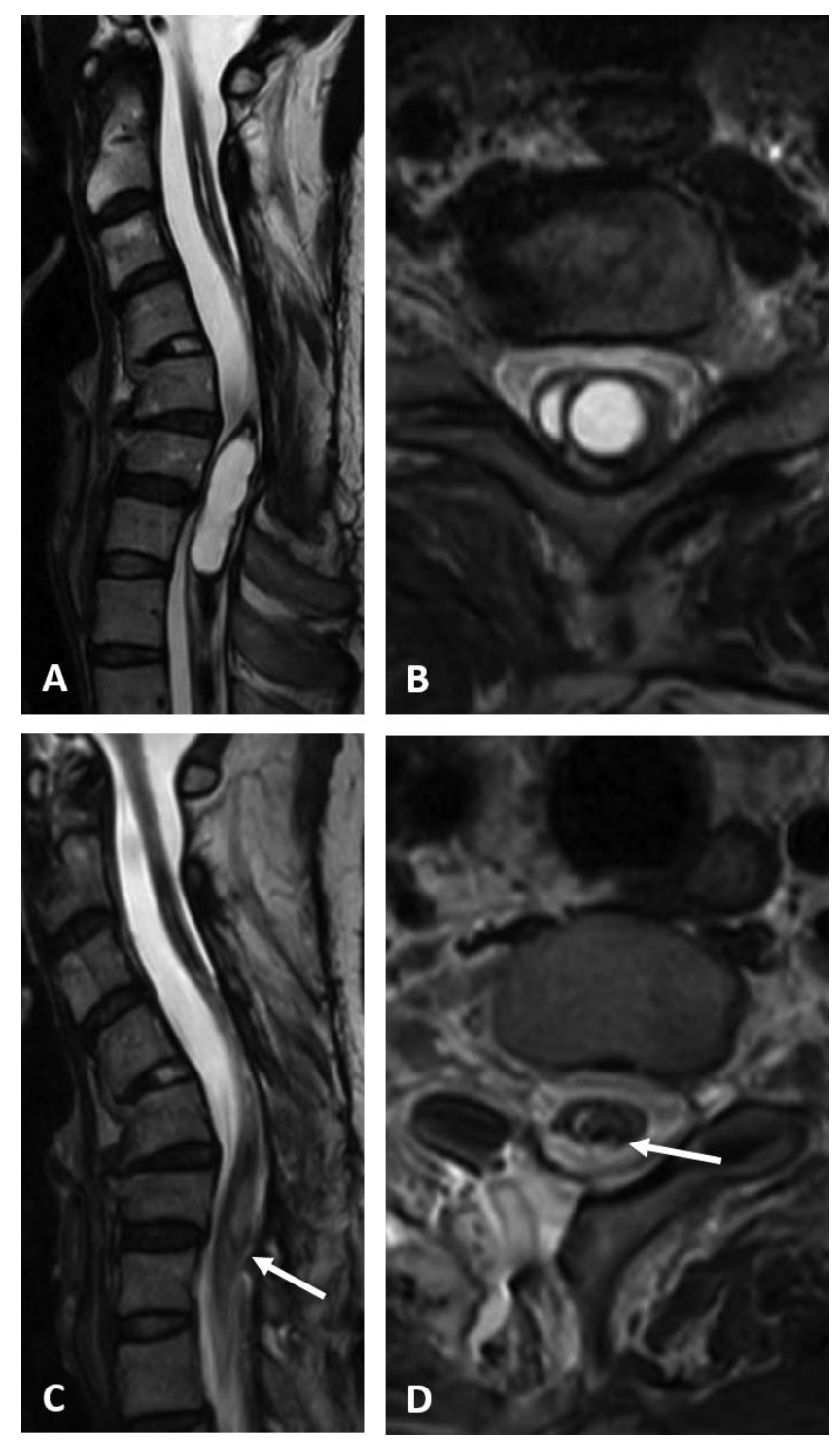

Figure 4. Case 3. (A) and (B) Preoperative magnetic resonance imaging T2 weighted sagittal and axial (at C7), showing large cervico-dorsal syrinx with thinning of the cord. (C) and (D) Postoperative magnetic resonance imaging T2 weighted sagittal and axial (at C7), showing resolution of syrinx with laminotomy defect and shunt tube in place (arrows).

materials. While many other shunting techniques have also been described in the literature, such as syringo-pleural and syringo-peritoneal shunting, they seem to have their own inherent shortcomings such as overdrainage, spinal cord tethering, and having to invade another body space and, hence, have not stood the test of time. ${ }^{8,21,23}$

The conventional method for performing syringo-subarachnoid shunting is by a standard open approach which uses a midline incision with bilateral muscle dissection, wide laminectomies, and large dural exposure. These techniques carry a higher risk of instability due to removal of posterior elements along with paraspinal muscle degeneration and denervation, as well as increased blood loss, postoperative pain, hospital stay, and delayed recovery. Complications such as delayed wound healing, infection, postoperative CSF leak, pseudomeningocele, and CSF fistula formation have also been documented to be higher. ${ }^{13-15}$

Minimally invasive techniques such as described in this report have the potential to mitigate these problems to a large extent. Ever since Foley et al popularized the minimally invasive microtubular endoscopic technique, it has been used extensively to treat degenerative diseases of the spine. ${ }^{24}$ Such techniques have also been recently used to treat intradural pathologies such as tumors with moderate to good results. ${ }^{25,26}$ Similarly, the same principles have been used to address this intramedullary pathology of syringomyelia.

Many surgeons have employed various techniques to minimize the risks involved in open approaches. Some have used unilateral muscle dissection and hemilaminectomy to reduce the incidence of instability. While these are not truly minimally invasive in its true sense, they seem to offer some advantage. ${ }^{9,27}$ However, others have used endoscopic routes for percutaneous insertion of syringo-pleural shunts, but these have inherent approach-related difficulties with poor visualization and blind entrance into the syrinx and pleura. ${ }^{28}$ Recently, Leschke et al have used a myringotomy tube instead of a shunt tube to reduce the risk of arachnoiditis and adhesions, but again, this was through a traditional open approach. ${ }^{12}$

Very few reports speak of using a minimally invasive expandable tubular retractor (X-Tube, Medtronic, Sofamor Danek, Memphis, TN) by O'Toole et al in 2007 and more recently by Gandhi and German in 2013 (Quadrant, Medtronic, Sofamor Danek, Memphis, TN). ${ }^{11,26}$

In the present report, a minimally invasive technique is described that employs the use of a smaller, fixed 22-mm tubular retractor (MetRx, Medtronic, Sofamor Danek, Memphis, TN). However, this MIS technique is generic to any sequential dilating tubular retractor with an attached flexible table mounted arm and not specific to the one used in this report. Specific intraoperative measures were taken to overcome the approach-related difficulties of operating through a narrow window. Adequate access to the cord was achieved by angling the tube medially, creating a laminar fenestration, and undercutting the base of spinous process. Epidural 
venous bleeding was controlled by using specific hemostatic agents. CSF leaks were avoided by water-tight dural closure and using fibrin glue with dural substitutes. Reduced postoperative dead space would also serve as an additional layer of protection for prevention of CSF leak. Since the muscles are only split and not dissected away, they tend to fall back and occlude any dead space.

In all the described cases, there were no postoperative complications such as CSF leak, meningitis, or wound infection, and no lumbar drain was used. Patients were mobilized on the first postoperative day and discharged on the third or fourth day. Neurological improvement was noted in terms of reduced spasticity and myelopathy symptoms. Radiologically, the syrinx was noted to have decreased in size in the immediate follow up.

There are limitations to this study. This is a short case series without significant long-term follow up. However, the aim of this study is not to report the outcomes of syringo-subarachnoid shunt in general, which has already been described in the literature in detail, yet we describe the effectiveness of an already established procedure through a novel, minimally invasive approach which has the potential to significantly reduce the overall morbidity, in view of the inherent approach-related benefits.

Further, it is important to note that syringosubarachnoid shunting is not always successful nor technically feasible if there is arachnoid tethering or scarring from previous trauma, infection, or inflammation. Syringo-pleural or syringo-peritoneal shunting is an accepted and effective alternative technique which is widely used.

\section{CONCLUSIONS}

This minimally invasive technique for treatment of syringomyelia seems to be an ideal approach for placement of syringo-subarachnoid shunts, as it provides direct access to the lesion with minimal collateral damage and wound-related complications.

\section{VIDEO AVAILABLE}

A video of a surgical technique of minimally invasive syringo-subarachnoid shunt being placed on the left side with laminotomy, durotomy, myelotomy at DREZ, placement of prefashioned shunt tube into syrinx cavity, dural closure, and overlay dural substitute. At the end, the track through the split muscle collapsing after removal of
MetRx tube and the skin wound are also shown. Video available at: https://drive.google.com/open? $\mathrm{id}=1 \mathrm{DNB} 0 \mathrm{TTKMssTZ16J7q1HK2XbI2fQ7SSc1.}$

\section{REFERENCES}

1. Flint G, Rusbridge C. Syringomyelia: A Disorder of CSF Circulation. Berlin; Heidelberg: Springer; 2014.

2. Heiss JD, Patronas N, DeVroom HL, et al. Elucidating the pathophysiology of syringomyelia. J Neurosurg. 1999;91(4):553-562. doi:10.3171/jns.1999.91.4.0553.

3. Milhorat TH. Classification of syringomyelia. Neurosurg Focus. 2000;8(3):E1. doi:10.3171/foc.2000.8.3.1.

4. Brodbelt AR, Stoodley MA. Post-traumatic syringomyelia: a review. J Clin Neurosci Off J Neurosurg Soc Australas. 2003;10(4):401-408.

5. Di Lorenzo N, Cacciola F. Adult syringomielia. Classification, pathogenesis and therapeutic approaches. $J$ Neurosurg Sci. 2005;49(3):65-72.

6. $\mathrm{Wu} \mathrm{T}$, Zhu Z, Jiang J, et al. Syrinx resolution after posterior fossa decompression in patients with scoliosis secondary to Chiari malformation type I. Eur Spine J. 2012;21(6):1143-1150. doi:10.1007/s00586-011-2064-3.

7. Iskandar BJ, Hedlund GL, Grabb PA, Oakes WJ. The resolution of syringohydromyelia without hindbrain herniation after posterior fossa decompression. $J$ Neurosurg. 1998;89(2):212-216. doi:10.3171/jns.1998.89.2.0212.

8. Batzdorf U. Primary spinal syringomyelia: a personal perspective. Neurosurg Focus. 2000;8(3):E7.

9. Gezen F, Kahraman S, Ziyal IM, Canakçi Z, Bakir A. Application of syringosubarachnoid shunt through key-hole laminectomy. Technical note. Neurosurg Focus. 2000;8(3):E10.

10. Carroll AM, Brackenridge P. Post-traumatic syringomyelia: a review of the cases presenting in a regional spinal injuries unit in the north east of England over a 5-year period. Spine. 2005;30(10):1206-1210.

11. O'Toole JE, Eichholz KM, Fessler RG. Minimally invasive insertion of syringosubarachnoid shunt for posttraumatic syringomyelia: technical case report. Neurosurgery. 2007;61(5 Suppl 2):E331-332; discussion E332. doi:10.1227/01. neu.0000303990.03235.81.

12. Leschke JM, Mumert ML, Kurpad SN. Syringosubarachnoid shunting using a myringotomy tube. Surg Neurol Int. 2016;7(Suppl 1):S8-S11. doi:10.4103/2152-7806.173559.

13. Zong S, Zeng G, Du L, Fang Y, Gao T, Zhao J. Treatment results in the different surgery of intradural extramedullary tumor of 122 cases. PLoS ONE. 2014;9(11):e111495. doi:10.1371/journal.pone.0111495.

14. Bresnahan LE, Smith JS, Ogden AT, et al. Assessment of paraspinal muscle cross-sectional area after lumbar decompression: minimally invasive versus open approaches. Clin Spine Surg. 2017;30(3):E162. doi:10.1097/BSD.0000000000000038.

15. Wong AP, Lall RR, Dahdaleh NS, et al. Comparison of open and minimally invasive surgery for intradural-extramedullary spine tumors. Neurosurg Focus. 2015;39(2):E11. doi:10. 3171/2015.5.FOCUS15129.

16. Iskandar BJ, Hedlund GL, Grabb PA, Oakes WJ. The resolution of syringohydromyelia without hindbrain herniation after posterior fossa decompression. Neurosurg Focus. 2000;8(3):1-5. doi:10.3171/foc.2000.8.3.5. 
17. Tator $\mathrm{CH}$, Briceno $\mathrm{C}$. Treatment of syringomyelia with a syringosubarachnoid shunt. Can J Neurol Sci. 1988;15(1):4857. doi:10.1017/S0317167100027190.

18. Ghobrial GM, Dalyai RT, Maltenfort MG, Prasad SK, Harrop JS, Sharan AD. Arachnolysis or cerebrospinal fluid diversion for adult-onset syringomyelia? A systematic review of the literature. World Neurosurg. 2015;83(5):829-835. doi:10. 1016/j.wneu.2014.06.044.

19. Davidson KA, Rogers JM, Stoodley MA. Syrinx to subarachnoid shunting for syringomyelia. World Neurosurg. 2018;110(Feb 1):e53-e59. doi:10.1016/j.wneu.2017.09.205.

20. Tassigny D, Abu-Serieh B, Fofe DT, Born J, Milbouw G. Shunting of syringomyelic cavities by using a myringotomy tube: technical note and long-term results. World Neurosurg. 2017;98(Feb 1):1-5. doi:10.1016/j.wneu.2016.10.067.

21. Sgouros S, Williams B. A critical appraisal of drainage in syringomyelia. J Neurosurg. 1995;82(1):1-10. doi:10.3171/jns. 1995.82.1.0001.

22. Batzdorf U, Klekamp J, Johnson JP. A critical appraisal of syrinx cavity shunting procedures. $J$ Neurosurg. 1998;89(3):382-388. doi:10.3171/jns. 1998.89.3.0382.

23. Schaan M, Jaksche H. Comparison of different operative modalities in post-traumatic syringomyelia: preliminary report. Eur Spine J. 2001;10(2):135-140. doi:10.1007/s005860000197.

24. Foley KT, Smith MM, Rampersaud YR. Microendoscopic approach to far-lateral lumbar disc herniation. Neurosurg Focus. 1999;7(5):e5. doi:10.3171/foc.1999.7.6.6.

25. Tredway TL. Minimally invasive approaches for the treatment of intramedullary spinal tumors. Neurosurg Clin $N$ Am. 2014;25(2):327-336. doi:10.1016/j.nec.2013.12.010.

26. Gandhi RH, German JW. Minimally invasive approach for the treatment of intradural spinal pathology. Neurosurg Focus. 2013;35(2):E5. doi:10.3171/2013.5.FOCUS13163.
27. Colak A, Boran BO, Kutlay M, Demirican N. A modified technique for syringo-subarachnoid shunt for treatment of syringomyelia. J Clin Neurosci Off J Neurosurg Soc Australas. 2005;12(6):677-679. doi:10.1016/j.jocn.2004.09.015.

28. Guest JD, Silbert L, Casas CE. Use of percutaneous endoscopy to place syringopleural or cystoperitoneal cerebrospinal fluid shunts. J Neurosurg Spine. 2005;2(4):498-504. doi:10.3171/spi.2005.2.4.0498.

Disclosures and COI: There are no known conflicts of interest associated with this publication, and there has been no significant financial support for this work that could have influenced its outcome. This manuscript is original, has not been published before, and is not currently being considered for publication elsewhere.

Corresponding Author: Akshay Hari, DNB, Department of Neurosurgery, Aster CMI Hospital, 43/2, New Airport Road, NH.7, Hebbal, Sahakara Nagar, Bengaluru, Karnataka 560092, India. Phone: +919480549069; Email: akshayhari@gmail. com.

Published 30 April 2020

This manuscript is generously published free of charge by ISASS, the International Society for the Advancement of Spine Surgery. Copyright (c) 2020 ISASS. To see more or order reprints or permissions, see http://ijssurgery.com. 